\title{
Processos e práticas decoloniais na formação de professores
}

\author{
Procesos y prácticas descoloniales en la formación docente \\ Decolonial processes and practices for teach tranining
}

\author{
Dr $^{\mathrm{a}}$. Alessandra Fontes C. da Rocha K. Pereira ${ }^{1}$
}

\begin{abstract}
Resumo
O objetivo deste trabalho é refletir sobre possíveis práticas decoloniais na formação de professores, especificamente no curso de Letras (Português - Literaturas). É na atuação com disciplinas de formação de professores $^{2}$ que a importância desta reflexão vem à tona, pois é possível observar o quanto há sujeitos marcados pelo sistema de ensino da Pedagogia Tradicional, a famosa educação bancária, denominada por Paulo Freire, e o quanto os mesmos estão dispostos a reproduzir tal sistema de ensino, sem perceber outras possibilidades para uma prática docente mais significativa no sentido de formar cidadãos críticos e lúcidos. Não se trata, neste caso, da recusa por um trabalho decolonial, mas, sim, da falta de experiência e vivência de situações de ensino-aprendizagem que levem a um distanciamento e enfraquecimento do instruir em oposição ao apreender na escola. Diante desta situação, é imprescindível, nas salas de aula das universidades, nos cursos de licenciaturas, discutir, refletir e apresentar ações pedagógicas que desvelem processos neocolonizadores educacionais e pensar novas práticas que contribuam para um movimento de resistência e ruptura a favor da decolonização da escolarização.
\end{abstract}

PALAVRAS-CHAVE: Formação de professores; práticas docentes; decolonização.

\section{Resumen}

El propósito de este trabajo es discutir posibles prácticas descoloniales en la formación docente, específicamente en el curso de Letras (Portugués - Literatura). Es em el funcionamiento de los cursos de formación de profesores que la importancia de esta reflexión surge, es posible ver cuánto és el sujeto marcado por el sistema de enseñanza de la pedagogía tradicional, la famosa educación bancaria, como llama por Paulo Freire, y cómo la mismos que están dispuestos a reproducir dicho el sistema educativo, sin darse cuenta a otras posibilidades para una práctica docente más significativa con el fin de formar

1 Doutora em Estudos de Literatura; professora de Didática e Prática de Ensino Português - Literaturas; Universidade Federal do Rio de Janeiro; Rio de Janeiro; Rio de Janeiro; Brasil; contato: profa.alessandra.fontes@gmail.com; trabalho apresentado no I Seminário Latino-Americano de Estudos em Cultura - SEMLACult, Foz do Iguaçu/PR, Brasil, 2017.

2 No meu caso, a atuação é especificamente com licenciandos do curso de Letras (Português - Literaturas) da Universidade Federal do Rio de Janeiro. 
ciudadanos críticos y lúcidos. Esta no es la negativa de una obra descolonial, pero la falta de experiencia y la experiencia de situaciones de enseñanza-aprendizaje que conducen a la separación y el debilitamiento de la instrucción en oposición a aprender en la escuela. En esta situación, el imperativo, en las aulas de las universidades en cursos de grado, discutir, reflexionar y presentar acciones pedagógicas que revelan procesos educativos Neocolonistas y pensar en nuevas prácticas que contribuyen a un movimiento de resistencia y romper a favor de la escolarización de la descolonización.

PALABRAS CLAVE: la formación del profesorado; prácticas de enseñanza; descolonización.

\begin{abstract}
The purpose of this paper is to discuss possible decolonial practices in teacher education, specifically in the literature course (Portuguese - Literature). It is in the operation of teacher training courses that the importance of this reflection arises, it is possible to see how much the subject is marked by the system of teaching of traditional pedagogy, the famous banking education, as called by Paulo Freire, and how The same ones that are willing to reproduce said educational system, without realizing other possibilities for a more meaningful teaching practice in order to train citizens critical and lucid. This is not the denial of a decolonial work, but the lack of experience and experience of teaching-learning situations leading to separation and weakening of instruction as opposed to learning in school. In this situation, the imperative, in the classrooms of the universities in undergraduate courses, discuss, reflect and present pedagogical actions that reveal Neocolonist educational processes and think of new practices that contribute to a resistance movement and break in favor of the schooling of Decolonization.
\end{abstract}

KEY WORDS: teacher training; Teaching practices; decolonization.

\title{
1. "Levar de um lugar para outro": A formação de professores por um viés decolonizador
}

Dizem que educar, etimologicamente, significa "levar de um lugar para outro". Concordo. Aliás, creio ser às vezes importante recuperar a etimologia dos conceitos, quando isso significa uma recuperação da densidade da vivência que se tem, vivência sempre expressa com palavras. "Levar de um lugar para outro", está aí uma vivência cuja densidade pode significar um aumento incalculável de experiências, configurando aquilo que fundamenta um processo de ensino-aprendizagem realmente humano. (NOVASKI, 1994, p. 11) 
A epígrafe deste artigo reflete a concepção de educação e de processo ensinoaprendizagem que iremos empreender em nossas reflexões: uma educação e um processo ensino-aprendizagem realmente humanos para o humano, incluindo vivências e experiências na vida dos estudantes que os levem de um lugar para outro.

É o movimento de "levar de um lugar para outro", como significado etimológico de educar $^{3}$, que servirá como ponto de partida para a análise das políticas públicas brasileiras de educação, principalmente no que se refere às políticas públicas educacionais que envolvem o sistema público de ensino do município do Rio de Janeiro e as práticas docentes sobre as quais temos notícias a partir das observações de licenciandos ${ }^{4}$ no período de estágio supervisionado. De onde e para onde nossos estudantes estão sendo levados, estando eles na educação básica ou no ensino superior?

A questão acima é apenas uma das muitas que nos fazemos ao pensar em uma educação que seja parte de uma pedagogia decolonial em suas práticas e políticas, ou seja, formas de transformar a sala de aula num lugar de resistência aos modelos de políticas públicas de educação que visam à padronização bancária do processo ensino-aprendizagem. Para Boaventura de Souza Santos, esse processo de decolonialidade seria "um conjunto de práticas e discursos que desconstroem a narrativa colonial como foi escrita pelo colonizador, e tenta substituí-la por narrativas escritas do ponto de vista do colonizado" (SANTOS, 2002, p. 13). Mas, para isso, é necessário que o sujeito seja livre para ser e pensar a partir de suas experiências, suas crenças, suas opiniões, lugar onde está inserido, sua língua e suas linguagens, construindo um movimento oposto ao da monocultura do pensamento.

O questionamento acima também é o primeiro passo para analisarmos ações pedagógicas que só reafirmam o neocolonialismo da educação, que, ao contrário de levar para algum lugar, só fixam os sujeitos em formação em um terreno de manutenção das hierarquias já estabelecidas aos "condenados da terra"5 . É no início da obra Pedagogia da Autonomia que Paulo Freire proclama seu posicionamento ético e o que deveria ser o de educadores e educadoras.

\footnotetext{
"Daí o tom de raiva, legítima raiva, que envolve o meu discurso quando me refiro às injustiças a que são submetidos os esfarrapados do mundo (...) Em tempo algum pude ser um observador 'acinzentadamente' imparcial, o que, porém, jamais me afastou de uma posição rigorosamente ética (...) O meu ponto de vista é o dos "condenados da Terra", o dos excluídos. (...) Este pequeno livro

${ }^{3}$ Segundo Augusto João Crema Novaski em "Sala de aula: uma aprendizagem do humano".

${ }^{4}$ Neste caso, licenciandos do curso de Letras (português - literaturas), da UFRJ.

5 A expressão apresenta um diálogo com o pensamento de Frantz Fanon, quando Freire utiliza em algumas passagens a expressão "condenados da terra" para se referir aos oprimidos; excluídos.
} 
se encontra cortado ou permeado em sua totalidade pelo sentido da necessária eticidade que conota expressivamente a natureza da prática educativa, enquanto prática formadora. Educadores e educandos, não podemos, na verdade, escapar à rigorosidade ética. Mas, é preciso deixar claro que a ética de que falo não é a ética menor, restrita do mercado, que se curva obediente aos interesses do lucro." (FREIRE, 1997, p. 15-17)

O autor aponta a importância de uma reflexão crítica e da afirmação de um compromisso com uma ação pedagógico-política, tendo como alvo os seres humanos negados, excluídos do sistema hegemônico vigente. Ele ainda esclarece que "[...] é preciso deixar claro que a ética de que falo não é a ética menor, restrita do mercado, que se curva obediente aos interesses do lucro.”. Freire alerta para uma ética do povo e para o povo; do humano e para o humano.

Nesse sentido, faz-se emergencial a discussão da formação daqueles que já estão nas cadeiras universitárias e que, após mais algum tempo de formação, ocuparão o cargo de docente e terão uma atuação, que se pretende, constituinte da educação libertadora. Segundo Vasconcelos e Brito (2009), a educação libertadora é aquela que:

[...] envolve a formação do educando em um ser crítico, que pensante, agente e interveniente no mundo, sente-se capaz de transformá-lo. Para isto, precisa ter conhecimento do mundo e analisá-lo criticamente. Configura-se como o crescimento da consciência crítica; é poder de domínio na construção de uma sociedade mais igualitária, onde as pessoas realizem plenamente seu potencial humano (VASCONCELOS E BRITO, 2009, p. 88).

É apenas com uma educação que privilegie a formação plena do potencial humano que teremos a chance de um engajamento ativo do indivíduo atuando como peça principal para a reflexão e a transformação de seu mundo, frente a problemas sociais, políticos, econômicos e culturais, além do apagamento do processo de silenciamento que algumas classes sofrem em nossa sociedade.

Desse modo, as práticas docentes devem ser pautadas em uma educação como prática da liberdade, excluindo qualquer vestígio da famosa educação bancária que, segundo Freire:

[...] conduz os educandos à memorização mecânica do conteúdo narrado. Mais ainda, a narração os transforma em vasilhas, em recipientes a serem enchidos pelo educador. Quanto mais vá enchendo os recipientes com seus depósitos, tanto melhor educador será. Quanto mais se deixem docilmente encher, tanto melhores educandos serão. (FREIRE, 2005, p. 66) 
Além de memorizar mecanicamente, nossos estudantes são comparados a vasilhas e recipientes que devem ser preenchidos e depositados com parcelas de conteúdos que são ensinados por seus professores de forma opressora, onde o docente é visto como o dono do saber e o único com autoridade em sala de aula para falar algo e ensinar. Já o discente, nesta prática, é inibido a qualquer tipo de troca e de diálogo. Assim, tem-se a formação na sala de aula, onde, muitas vezes, um finge que ensina e o outro finge que aprende, a partir de processos bancários da educação como instrumentos de opressão.

Ainda na pedagogia tradicional, o educador é o detentor do conhecimento, sendo dele a responsabilidade de transferir tudo o que sabe aos estudantes. Estes últimos têm como única opção a tarefa de: “[...] receberem os depósitos” [realizados pelo educador], guardá-los e arquivá-los. Margem para serem colecionadores ou fixadores das coisas que arquivam" (FREIRE, 2005, p. 66).

É a partir dessas características que podemos perceber o quanto a educação e a sala de aula reproduzem a cultura do silêncio imposta pela nossa formação colonial. Vale aqui ressaltar também a marca da docilização destacada por Freire: "Quanto mais se deixem docilmente encher, tanto melhores educandos serão." (FREIRE, 2005, p. 66) (grifo meu). Tal perspectiva nos faz mencionar a obra Vigiar e Punir, de Michel Foucault, na qual o autor apresenta reflexões sobre as formas de disciplinarização das pessoas em diferentes instituições sociais, como por exemplo: na escola, na igreja, na família, no hospital,..., e as consequências desse processo para a vida de cada indivíduo.

É na escola, principalmente na sala de aula, que nos interessará refletir sobre a construção desse corpo dócil, ou seja, aqueles corpos obedientes, que se deixam instruir sem contestações. Sendo a docilização mais uma característica da educação bancária, é necessário perceber quais as práticas pedagógicas que ainda acontecem em nossas escolas e que, mesmo de forma velada, produzem estudantes "bonzinhos" que nada questionam e apenas reproduzem o que é orientado por seus professores.

Além da docilização dos corpos, sendo por meio de violência física ou simbólica, o que também nos interessa é pensar nas formas utilizadas para domar a consciência do ser humano. Partindo da ideia de que não só o corpo, mas a mente, os pensamentos dos sujeitos também são vigiados e punidos nas salas de aula, passamos dos efeitos da palmatória aos resultados de práticas docentes que auxiliam na padronização e mecanização dos conhecimentos trabalhados nas escolas, a fim de formar sujeitos passivos e condenados à submissão, à aceitação e à alienação, ou seja, corpos úteis para a manutenção da hierarquização existente no campo social. Segundo Medina, 
A escola é, em grande escala, aquilo que as forças dominantes da sociedade desejam que ela seja. No sentido oficial, digamos assim, uma de suas funções fundamentais é manter o controle social através da estabilidade e do ajustamento. [...] Isto não quer dizer que a escola seja uma instituição estática e absolutamente reprodutiva do que já existe. Ela muda e se renova constantemente à medida que as contradições sociais obrigam o rearranjo da postura ou do discurso ideológico da classe dominante. [...]. Portanto, se vivemos num sistema capitalista, dependente, altamente hierarquizado em níveis sociais, não só a escola como também o homem, o corpo, e suas manifestações culturais, serão produtos ou subprodutos das estruturas que caracterizam este sistema (MEDINA, 2000, p. 19).

Por um lado, temos a escola que se isola de seu exterior, partindo o mundo em dois: o dentro e o fora do espaço escolar; os muros altos para a delimitação desse espaço; o local assumido por discentes e docentes; os exames e os registros avaliativos dos estudantes, que tentam colocar todos em uma mesma forma e os que não se adéquam sofrem as devidas punições. Por outro, temos as políticas públicas de educação passando também por um processo de padronização internacional, como por exemplo: o sistema PISA (Programme for International Studant Assiment), que garante a participação de 32 países em testes internacionais para o estabelecimento de níveis de aprendizado. Segundo Araújo,

[...] por exemplo, a fila, a carteira, o treino para a escrita, os exercícios com dificuldades crescentes, a repetição, a presença num tempo e num espaço recortados, a punição pelo menor desvio de conduta, a vigilância por parte de um mestre ou monitor, as provas, os exames, os testes de aprendizagem e de recuperação, o treinamento dentro de padrões e normas fixos. $E$ mais, os resultados dos esforços pedagógicos sendo permanentemente avaliados por critérios também eles padronizados, leva a uma simples análise de boletins, que sirva para medir os casos que desviam, portanto, serve para marcar, excluir, normalizar (ARAÚJO, 2002, p. 79).

Somado a isso tudo, ainda temos a figura do professor ou futuro professor que se apresenta como sujeito, muitas vezes, produto do sistema de ensino da Pedagogia Tradicional, a famosa educação bancária, denominada por Paulo Freire, e que se mostra disposto a reproduzir tal sistema de ensino, sem perceber outras possibilidades para uma prática docente mais significativa no sentido de formar cidadãos críticos e lúcidos. Diante deste cenário, nos resta começar pela formação daqueles que um dia irão formar e que poderão andar na contramão do processo de mecanização do processo ensino-aprendizagem que muitos países vivenciam. 
Ainda sobre os licenciandos e as marcas que trazem de uma pedagogia tradicional, devemos salientar que não se trata aqui da recusa por um trabalho decolonial, mas, sim, da falta de experiência e vivência de situações de ensino-aprendizagem que levem a um distanciamento e enfraquecimento do instruir em oposição ao apreender na escola. Diante desta situação, é imprescindível, nas salas de aula das universidades, nos cursos de licenciaturas, discutir, refletir e apresentar ações pedagógicas que desvelem processos neocolonizadores educacionais e pensar novas práticas que contribuam para um movimento de resistência e ruptura a favor da decolonização da escolarização, buscando oferecer uma educação emancipatória dos sujeitos.

\section{Da teoria à prática: os jogos e as atividades lúdicas como estratégias para pensar novas práticas docentes}

É na perspectiva de um ensino que estimule o pensamento e a reflexão dos estudantes que relatamos experiências de ações pedagógicas no campo da Didática e Prática de Ensino, especificamente do curso de Letras, habilitação Português - Literaturas, da Universidade Federal do Rio de Janeiro, que levem os licenciandos a refletir sobre a profissão docente e a importância da atuação no magistério com práticas que sirvam para combater padrões educacionais que valorizem determinada cultura em detrimento de outra; que empreguem modelos eurocêntricos; que postulem uma única verdade; e que façam da escola uma via de mão única, onde o professor é tido como o detentor do saber.

Vale lembrar que esse combate não é pensado pelos licenciandos apenas a partir das leituras de textos teóricos. Além das referências bibliográficas ${ }^{6}$ indicadas em sala de aula, os estudantes são estimulados a participar do movimento teoria - prática - teoria. Assim, depois de cada leitura e discussão de uma obra indicada, há a parte prática denominada de oficina e o retorno às discussões pautadas na teoria.

É durante as oficinas que os licenciandos são encorajados a romper com metodologias tradicionais de ensino e criarem seus próprios métodos, técnicas e atividades para o ensino de Língua Portuguesa e Literaturas, a fim de que o processo ensino-aprendizagem promova não

\footnotetext{
${ }^{6}$ Obras selecionadas por mim, professora da disciplina Didática de Língua Portuguesa - Literaturas, para compor a ementa e o cronograma do curso. A seleção é feita de acordo com a linha de interesse apresentada neste artigo: a reflexão, a análise e a construção de práticas docentes que viabilizem a formação de sujeitos críticos e lúcidos.
} 
só conhecimento da língua e de suas literaturas, mas também habilidades para pensar, refletir, produzir e, principalmente, criar a oportunidade do estudante, ainda na educação básica, ser autor de sua própria história.

Este investimento se justifica pelo fato de vivermos em uma cultura de aplicação e apreensão do conhecimento pré-elaborado e poucas são as possibilidades de mudança de um sistema que está pautado na quantidade de informação em detrimento da qualidade, bem como das possíveis aberturas que um assunto, considerado polêmico ou não, possa causar nas bases de uma sociedade que julgamos conhecer tão bem. É desta premissa e a partir destas questões que nasce a tentativa pedagógica de vincular os atos de ler, pensar e escrever, juntamente com a autoria do sujeito, principalmente de um sujeito crítico.

Dessa forma, o momento de formação, enquanto professor, provoca a reflexão sobre como a disciplina Língua Portuguesa, por exemplo, mesmo tão engessada dentro de um currículo mínimo e de conteúdos programáticos pode oferecer instrumentos que vão além do conhecimento gramatical e de funcionamento da língua materna.

Tendo o texto como grande protagonista das aulas e não o utilizando apenas como mero pretexto para o ensino de gramática, como Geraldi (2006) alerta em O texto na sala de aula, os futuros professores são estimulados a elaborar planejamentos de aulas, projetos e ações pedagógicas que valorizem a leitura de mundo de seus estudantes e provoquem a visão crítica dos mesmos em relação aos conhecimentos de língua, diferentes linguagens e literaturas.

Retomando as questões sobre o ensino de gramática, ressaltamos aquilo que os Parâmetros Curriculares Nacionais de Língua Portuguesa destacam:

[...] não se deve sobrecarregar os alunos com um palavreado sem função, justificado exclusivamente pela tradição de ensiná-lo. O critério do que deve ser ou não ensinado é muito simples: apenas os termos que tenham utilidade para abordar os conteúdos e facilitar a comunicação nas atividades de reflexão sobre a língua excluindo-se tudo o que for desnecessário e costuma apenas confundir os alunos (PCN, 1998a, p.60).

Percebemos que os próprios PCN's estimulam um trabalho de reflexão em detrimento da memorização de regras, principalmente no que concerne a norma padrão da Língua Portuguesa, apontando não serem tão eficazes as famosas listas de regências verbais - tão memorizadas por nossos estudantes, a fim de ter sucesso nos exames -, os exercícios de análise sintática ou atividades com frases soltas, nas quais os discentes devem preencher lacunas com verbos, pronomes, artigos e outros itens gramaticais que estão "vivos" (em uso) 
em textos autênticos e que podem ser vistos e ter seus usos pensados a partir da leitura, servindo de suporte para discussão não só do tema e assunto abordados, mas, também, ajudarem na análise de aspectos gramaticais que compõem o texto e o fazem ganhar existência. Segundo Possenti,

\begin{abstract}
Falar contra a "gramatiquice" não significa propor que a escola só seja "prática", não reflita sobre questões de língua. Seria contraditório propor esta atitude, principalmente porque se sabe que refletir sobre a língua é uma das atividades usuais dos falantes e não há razão para reprimi-la na escola. Trata-se apenas de reorganizar a discussão, de alterar prioridades (discutir os preconceitos é certamente mais importante do que fazer análise sintática - eu disse mais importante, o que significa que a análise sintática é importante, mas é menos ... ). Além do mais, se se quiser analisar fatos de língua, já há condições de fazê-lo segundo critérios bem melhores do que muitos dos utilizados atualmente pelas gramáticas e manuais indicados nas escolas (POSSENTI, 1999, p.55-56).
\end{abstract}

Assim, o objetivo de pensar e propor práticas pedagógicas a partir de jogos e atividades lúdicas não é o de colocar nova roupagem na "gramatiquice"; ou, no campo das literaturas, suavizar a historiografia e a memorização de movimentos literários, principais características, autores e principais obras; ou, no campo da produção textual, mascarar as "gavetas" criadas para colocar cada gênero discursivo em seu lugar com suas características e funções, apontando para uma falta de interação entre eles. A finalidade da proposta aqui apresentada é justamente romper com todas essas barreiras que desestimulam o estudo de língua e o envolvimento do estudante em sala de aula, principalmente nas aulas de Português. Travaglia apresenta bem o que seria o propósito das atividades com jogos e ludicidade.

\begin{abstract}
Nossa sugestão é que o ensino teórico, que muito comumente predomina nas aulas de Português, deve ceder espaço para os outros tipos de atividade, ocupando um mínimo do tempo disponível. Quando se trabalha com o ensino teórico, sugerimos que ele deve ter objetivos, tais como: a) facilitar, no ensino, a referência a elementos da língua, mas não deve ser cobrado dos alunos, sobretudo no Ensino Fundamental e em especial em suas séries iniciais $\left(1^{\mathrm{a}}\right.$ a $\left.4^{\mathrm{a}}\right)$; portanto, ser um instrumento de mediação e não um fim em si; b) ser objeto de uma cultura científica necessária na vida moderna; c) ser usado como um instrumento para ensinar a pensar (objetivo geral da educação e não um objetivo de ensino de língua) (TRAVAGLIA, 2003, p.60).
\end{abstract}

Toda a defesa de Travaglia sobre o ensinar a pensar como objetivo da educação nos orienta não só para as séries iniciais, mas, também, para o segundo segmento do ensino 
fundamental e para o ensino médio, principalmente por fazerem parte dos anos escolares que os professores formados no curso de Letras ${ }^{7}$ estão habilitados a trabalhar.

Os anos escolares aqui em questão também apresentam urgência no contato com novas propostas e ações pedagógicas, pois já chegaram ao ponto de serem "treinados" para os famosos exames ${ }^{8}$ que garantirão uma vaga no ensino superior. É justamente nesses anos escolares, principalmente no ensino médio, que o "adestramento" começa a fim de se ter êxito na continuidade da vida acadêmica.

Além dos exames externos, como por exemplo: o ENEM, há também as provas e testes ao longo do período escolar. Nesses casos, temos o ensino tradicional da língua mais evidente e com maior ênfase em normas fora da realidade e uso cotidiano dos estudantes. Neles, há uma maior cobrança em relação a nomenclaturas e itens teóricos supérfluos, excluindo uma maior produtividade do estudante no ato de responder às questões.

Porém, mesmo quando não se trata de perguntas, exercícios ou atividades que envolvem nomenclaturas e aspectos gramaticais, os jogos e as atividades lúdicas são sempre vistos como formas de revisar a teoria ou de ajudar a memorizar as regras da gramática. Esse último aspecto é muito vivenciado nos cursinhos preparatórios, onde professores utilizam paródia de músicas de sucesso como elemento de auxílio na fixação do conteúdo.

Apesar de ser uma maneira lúdica de trabalhar alguns aspectos gramaticais, ainda assim não é o que representa nossas escolhas no sentido de uma prática docente que seja significativa para o estudante em termos de produtividade. Neste artigo, nossa abordagem de ensino é a de uma gramática reflexiva ${ }^{9}$ e o de uma gramática de uso. Segundo Geraldi (1991, p.163), "A experiência do vivido passa a ser o objeto da reflexão; mas não pode ficar no vivido sob pena de esta reflexão não se dar. O vivido é ponto de partida para a reflexão".

Dessa forma, o estudante deve ser levado a usar regras e recursos da língua em diferentes variedades linguísticas, incluindo a variedade culta; a refletir sobre os efeitos de sentido de determinados elementos; a explicar, primeiramente tendo entendido, escolhas do falante ou produtor de um texto;...

\footnotetext{
${ }^{7}$ No caso deste trabalho, os professores formados ou em formação na Licenciatura em Letras (Português Literaturas).

${ }^{8}$ Atualmente, temos o Exame Nacional do Ensino Médio (ENEM) como a grande justificativa para todo o treinamento que os estudantes recebem nas escolas. A ideia central é fazer com que o estudante tenha um bom desempenho e, para isso, é preciso treinar resolvendo provas anteriores no menor período de tempo.

${ }^{9}$ Sobre o ensino de gramática, Travaglia (1996) afirma que o professor poderá trabalhar com quatro formas: a) gramática teórica b) gramática normativa c) gramática reflexiva d) gramática de uso.
} 
É somente assim que o estudante também experimentará um lugar ativo em sala de aula, tendo sua voz escutada pelo professor. Sobre o estudante ter a palavra em sala de aula, Geraldi (1991, p. 160-178) comenta: “A devolução da palavra ao aluno faz deste o condutor do seu processo de aprendizagem, assumindo-se como tal" e ainda acrescenta: "devolver a palavra ao outro significa querer escutá-lo. A escuta não é uma atitude passiva, a compreensão do outro envolve, segundo Bakhtin, uma atitude responsiva, uma contrapalavra".

É com essa atitude que vamos nos afastando da concepção de ensino da pedagogia tradicional que, ainda segundo Geraldi (1997, p. 20): “[...], o processo de ensinar centra-se na transmissão de conhecimentos. Isso supõe uma fonte que sabe, lugar ocupado exclusivamente pelo professor, e um receptáculo desse saber, lugar ocupado exclusivamente pelo aluno".

Sendo os jogos e as atividades lúdicas formas de criar espaços para os momentos de mais mediação e menos detenção do saber, serão eles os protagonistas das minhas aulas de Didática de Língua Portuguesa- Literaturas, a fim de proporcionar aos futuros professores experiências, ainda na formação acadêmica, que abram caminhos para práticas fundamentadas na participação efetiva do estudante e que apontem para uma compreensão de que os jogos e as atividades lúdicas nas aulas de língua, por exemplo, podem:

\footnotetext{
"ajudar as crianças a pensar que as palavras podem também ser usadas como peças de um jogo e que com elas podem fazer brincadeiras divertidas e até construírem um conto, poderão transformar a reticência de algumas crianças em relação à escrita em curiosidade e vontade de conhecer as palavras a fundo" (NORTON, 2001, p. 13).
}

\section{Momentos de criação: contribuições para o processo ensino-aprendizagem na formação de professores}

Passamos, agora, a descrever algumas das contribuições construídas por estudantes em processo de formação no curso de Licenciatura em Letras (Português - Literaturas), da Universidade Federal do Rio de Janeiro (UFRJ), nas aulas de Didática de Português Literaturas em consonância com a prática de ensino. Nesse período, os estudantes devem cumprir uma carga horária estabelecida pela instituição de ensino em alguma escola pública conveniada, inclui-se nessa relação o Colégio de Aplicação da UFRJ (CAP-UFRJ); escolas municipais e estaduais do Rio de Janeiro; além das escolas federais, devendo o discente ser 
orientado pelo professor responsável na instituição de ensino superior e supervisionado por um professor regente na educação básica.

Ainda na fase de estágio, na prática de ensino, o estudante é estimulado a fazer coparticipações nas turmas as quais acompanha na escola - campo de estágio - e a realizar uma regência, ou seja, ministrar uma aula com data e tema definidos junto com o professor regente de turma.

Como já relatado anteriormente, os estudantes, futuros professores, são expostos a textos teóricos e momentos de prática, principalmente criações de propostas que auxiliem o trabalho docente a gerar indivíduos conhecedores de sua língua materna e reflexivos em relação a seus usos. Por esse viés, teoria-prática-teoria, muitos estudantes conhecem possibilidades de ensino nunca antes experimentadas em sua vivência como estudante e nem imaginadas por eles, no momento de desempenharem o papel de docentes.

É com protagonismo na sala de aula que esses futuros professores são incentivados a sair das suas zonas de conforto. Ou seja, são solicitados a não seguir o trivial ou modelos já existentes de ensino; a evitar reproduzir o que viveram nas salas de aula durante a educação básica; ou mesmo a recusa de se inspirarem em metodologias tradicionais vividas no ensino superior.

A negação de todas essas práticas é o ponto de partida para os momentos de criação que acontecem uma vez por semana na sala de aula da universidade, com duração de três horas cada encontro. As aulas seguem um planejamento e um cronograma apresentados no início do período letivo. Neles, os estudantes já sabem quais as leituras que guiarão as discussões teóricas, as quais também servirão de suporte para as atividades práticas, chamadas por mim de oficinas.

A cada oficina, os futuros professores são encorajados a refletir sobre a profissão docente; a elaborar planos de aula e ministrar as aulas para seus colegas de classe, a fim de perceber o quanto é importante um bom planejamento e pensar em possíveis ajustes em suas próprias elaborações, além de fazer e receber avaliações de seus pares; a propor projetos pedagógicos; a criar jogos e atividades lúdicas e a testá-los, primeiramente, na sala de aula da universidade com seus colegas de classe e, posteriormente, a executá-los nas salas de aula dos campos de estágio, caso seja permitido pelo professor regente; a analisar o papel da gramática normativa na sala de aula durante o ensino de Língua Portuguesa; a conhecer os possíveis usos e organizações das diferentes tipologias textuais e gêneros discursivos; a analisar materiais didáticos e perceber como é conduzido o ensino por ele; e a compreender o que é a 
sala de aula, qual o papel desempenhado pelo professor e o que representa a presença do estudante em sala de aula.

São com essas inquietações que muitos estudantes passam por grandes transformações no sentido de perceberem o quanto o espaço escolar pode privá-los de algumas práticas e guiá-los a outras. É com muitos questionamentos e reflexões feitas em sala de aula acompanhadas das vivências nos estágios que muitos futuros professores começam a perceber o quanto o caminho trilhado pelos professores por uma educação libertadora pode ser difícil.

Muitos são os obstáculos encontrados sejam eles por parte da gestão escolar que não tem seu projeto político pedagógico bem definido ou o definiu de maneira a fazer o sistema funcionar; sejam por parte das políticas públicas criadas por esse mesmo sistema, fazendo com que cada discente se torne um número e não um indivíduo, que as singularidades e individualidades de cada um ou de cada comunidade escolar se tornem homogêneas; sejam pelos exames únicos e padrões criados para serem aplicados em uma grande rede de ensino que atende a milhares de estudantes que a cada bimestre são medidos de forma padronizada, a fim de segregar ou mesmo excluir os que não se encaixam nos padrões, sendo o caso da Prova Brasil, Prova Rio, SAERJ, Saerjinho, ENEM, entre outros.

Apesar das dificuldades encontradas, o andar na contramão de uma educação que, muitas vezes, trabalha para que os sujeitos continuem subalternos não é impossível e deve ser exercitada pelos futuros professores, a começar por aqueles que trabalham com uma ferramenta poderosa para que a emancipação aconteça: a Língua Portuguesa e seus usos. Os frutos desse tipo de trabalho são alguns exemplos que virão a seguir. São atividades elaboradas e executadas por licenciandos do curso de Letras (habilitação Português Literaturas).

A primeira atividade é um jogo intitulado Racha a Cuca, criado e desenvolvido pela licencianda Juliana Barros Nespoli. A atividade, aqui, descrita é indicada para o primeiro ano do ensino médio e pretende contribuir para uma revisão referente às aulas de produção textual. Para isso, considera-se que os conteúdos previamente abordados estavam associados à uma gradação textual, tendo sido os estudantes expostos ao estudo da coesão lexical (estratégia de referenciação pronominal ou por elipse, por exemplo), da estruturação sintática (ordem, fronteira e elementos constitutivos) e das relações semânticas (a construção de significados a partir da ambiguidade, por exemplo).

Ainda de acordo com a proposta criada pela licencianda, as regras do jogo são as seguintes: (1) Divisão da turma em dois grupos (no máximo três), A e B; (2) Cada grupo deve eleger um aluno, o líder, responsável por emitir as respostas do grupo; (3) Cada grupo deve 
responder a perguntas a partir da escolha de uma categoria e de um procedimento; (4) Cada líder terá vinte segundos para responder à pergunta, devendo consultar, durante esse tempo, os demais integrantes do seu grupo; (5) Caso uma das respostas de um dos grupos esteja correta, o grupo ganha a pontuação relativa ao procedimento escolhido, passando a vez para o outro grupo executar a tarefa da mesma forma; (6) Caso uma das respostas de um dos grupos esteja errada ou não haja resposta, o outro grupo terá vinte segundos para responder à pergunta e terá a chance de obter a pontuação.
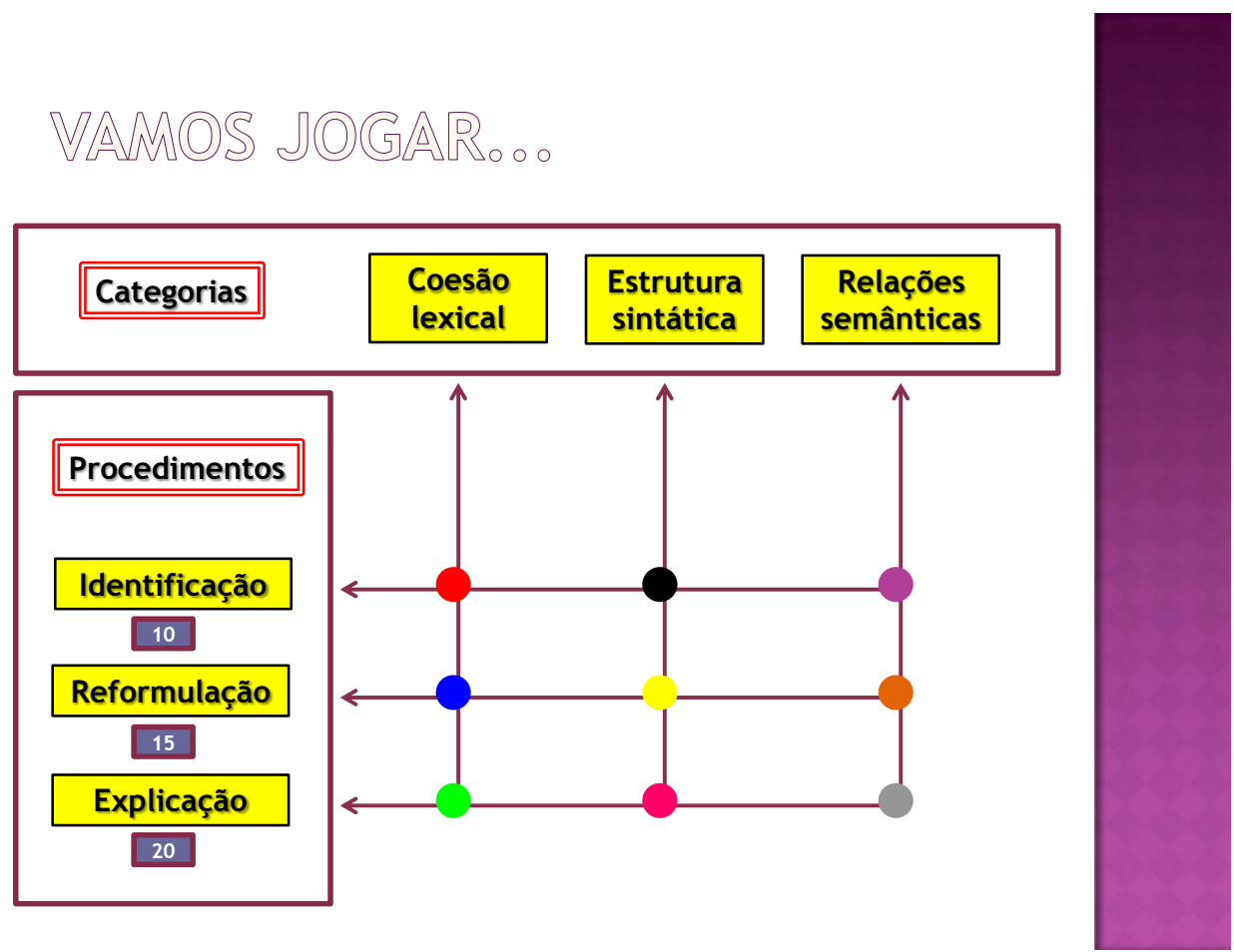

(Template do jogo elaborado pela licencianda Juliana Barros Nespoli)

Conforme as regras apresentadas acima, a atividade promove, a partir da escolha de uma categoria, de um procedimento (levando em consideração a pontuação diferenciada entre eles) e de uma cor, a reflexão sobre aspectos da língua, como nos exemplos abaixo: 
RELACult - Revista Latino-Americana de Estudos em Cultura e Sociedade

Revista Latinoamericana de Estudios en Cultura y Sociedad | Latin American Journal of Studies in Culture and Society V. 03, ed. especial, dez., 2017, artigo no 473 | relacult.claec.org | e-ISSN: 2525-7870

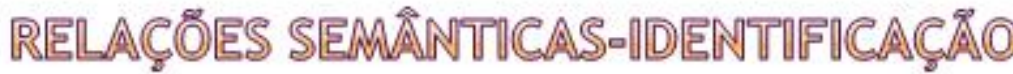

Questão: Indique a palavra que provoca os dois sentidos que a propaganda a seguir pode ter. Indique também quais sentidos são esses:

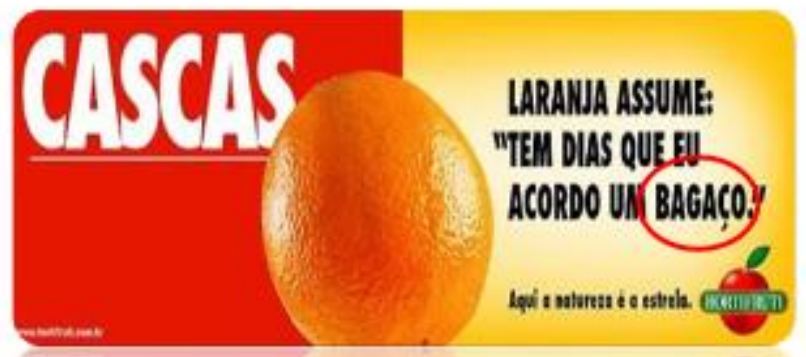

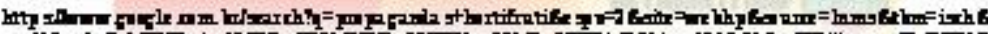

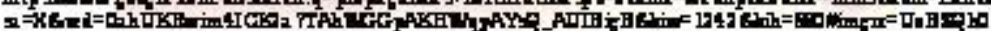

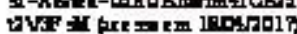

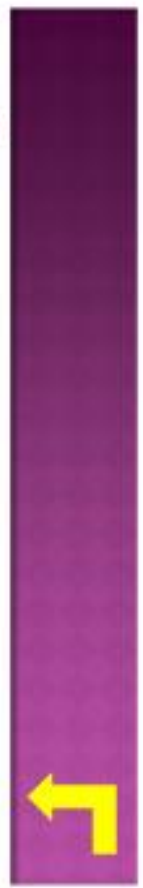

(Template do jogo elaborado pela licencianda Juliana Barros Nespoli)

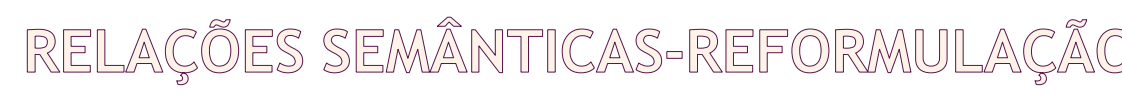

Questão: Reformule o título da notícia a seguir, eliminando a ambiguidade:

\section{Polícia cerca prédio com índios no Rio}

Liminar que garantia posse do imóvel de 1862 aos indígenas foi cassada; governo quer demoli-lo para fazer estacionamento e instalações da Copa

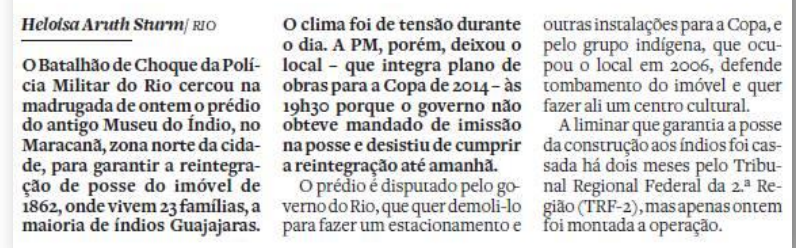

https://www.indios.org.br/pt/noticias?id=120114 (acesso em 18/04/2017)

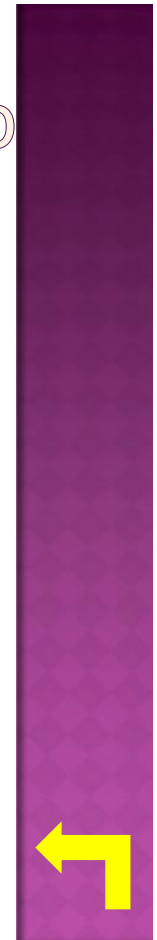

(Template do jogo elaborado pela licencianda Juliana Barros Nespoli) 
Outro exemplo é a atividade intitulada Jogo da Memória de Rimas. Elaborado pela licencianda Thamyres Perez. Indicado para turmas do sexto ano do ensino fundamental, o jogo segue a mesma regra do tradicional jogo da memória. Porém, ao invés de encontrar as palavras ou imagens iguais, os estudantes devem achar pares de palavras que rimem entre si e, encontrando as peças, devem criar, oralmente e por escrito, no mínimo, quatro versos com rimas que apresentem as palavras encontradas, promovendo a produção oral e, depois, a escrita criativa.
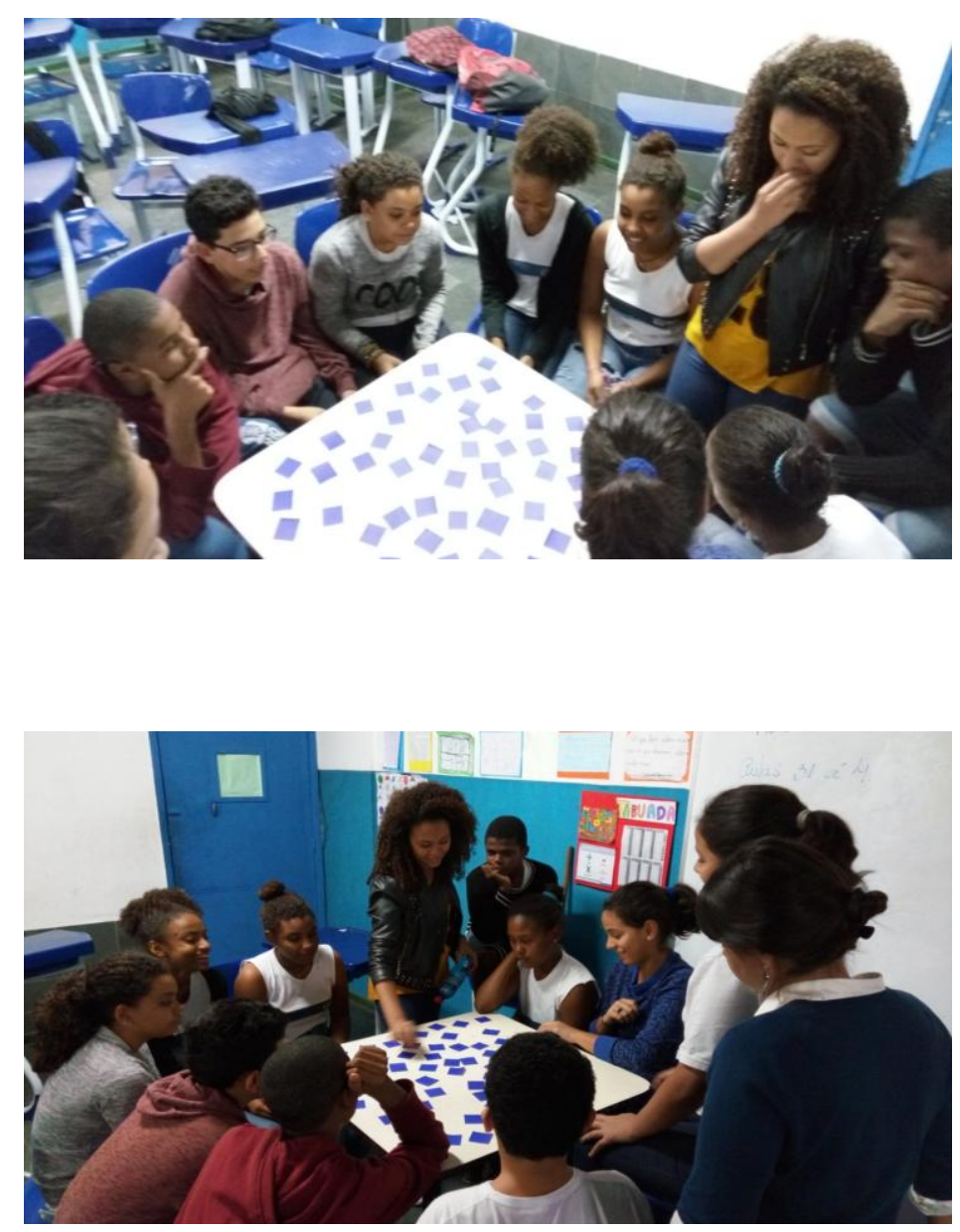

( O Jogo da Memória de Rimas, após ter sido jogado pelos licenciandos, é executado por outra licencianda, Thamires da Matta, com estudantes do ensino fundamental da Escola Municipal Finlândia, localizada no município do Rio de Janeiro) 


\section{Considerações finais}

O processo de formação de docentes, especialmente no decorrer da prática de ensino ${ }^{10}$, é, sem dúvida, um entre lugar da formação de sujeitos constituidores de ações pedagógicas que podem promover formas de decolonialidade no processo ensino-aprendizagem. As múltiplas experiências no desenvolvimento de práticas que possibilitam ampliar o aprendizado dos estudantes de ensino médio e ensino fundamental desassociadas do modelo bancário são formas constituidoras de um saber crítico.

Ao estabelecer estratégias de negociação entre os sistemas padronizadores da educação impostos pela instituição Estado e atividades que vislumbram o aprendizado significativo, os futuros professores tornam-se agentes transformadores que levarão para seus futuros grupos de estudantes um projeto de educação que encontra, nas fissuras da estrutura da educação normatizadora, oportunidades de estabelecer o pensamento crítico no processo ensino-aprendizagem.

\section{Referências}

ARAÚJO, Inês L. Da "pedagogização" à educação: acerca de algumas contribuições de Foucault e Habermas para a filosofia da educação. Revista Diálogo Educacional, Curitiba, v. 3 , n. 7 , p. 75-88, set./dez. 2002.

ARROYO, Miguel. Outros Sujeitos, Outras Pedagogias. Petrópolis, RJ: Vozes, 2012.

BRASIL. Ministério da Educação. Parâmetros Curriculares Nacionais: ensino médio. Brasília: MEC, 2000.

Secretaria de Educação Fundamental. Parâmetros Curriculares Nacionais: primeiro e segundo ciclos do ensino fundamental: Língua Portuguesa. Secretaria de Educação Fundamental. Brasília: MEC/SEF, 1998. Secretaria de Educação Fundamental. Parâmetros Curriculares Nacionais: terceiro e quarto ciclos do ensino fundamental: Língua Portuguesa. Secretaria de Educação Fundamental. Brasília: MEC/SEF, 1998.

\footnotetext{
${ }^{10}$ Momento do cumprimento do estágio obrigatório.
} 
FANON, Frantz. Os Condenados da Terra. $2^{\text {a }}$ Ed. Rio de Janeiro: Civilização Brasileira, 1979.

FOUCAULT, Michel. Vigiar e Punir: nascimento da prisão. Trad. Lígia M. Ponde Vassalo. Petrópolis: Vozes, 1987.

FREIRE, Paulo. A educação como prática da liberdade. 23ª ed. Rio de Janeiro: Paz e Terra, 1999.

Pedagogia da autonomia: saberes necessários à prática educativa. $43^{\mathrm{a}}$ ed., São

Paulo: Paz e Terra, 2011.

. Pedagogia da esperança: um reencontro com a pedagogia do oprimido. Rio de Janeiro: Paz e Terra, 2005.

. Pedagogia da indignação: cartas pedagógicas e outros escritos. $1^{\mathrm{a}}$ ed. São Paulo: Editora UNESP, 2000.

FREIRE, Paulo; SHOR, Ira. Medo e ousadia: o cotidiano do professor. $5^{\text {a }}$ edição. Rio de Janeiro: Paz e Terra, 1986.

GERALDI, João Wanderley. et. al. (org.) O texto na sala de aula. 4 ed. São Paulo: Ática, 2006.

MEDINA, João Paulo. O brasileiro e seu corpo: educação e política do corpo. Campinas: Papirus, 2000.

MORAIS, Regis de. Sala de aula: que espaço é esse? Ed. Papirus, 1994.

NETO, João Colares da Mota. Paulo Freire e o pós-colonialismo na educaçãoPopular latinoamericana. Revista Educação Online nº 14, p.25-38 , ago./dez. de 2013.

NORTON, C. Os mecanismos da escrita criativa. Lisboa: Temas e Debates - Actividades editoriais, 2001.

NOVASKI, Augusto João Crema. Sala de aula: uma aprendizagem do humano. In.:

MORAIS, Regis de. Sala de aula: que espaço é esse? Ed. Papirus, 1994.

PERINI, Mário A. Sofrendo a gramática. São Paulo: Ática, 1997.

POSSENTI, S. Por que (não) ensinar gramática na escola. $2^{\mathrm{a}}$ ed. Campinas: Mercado das Letras, 2012 [1996].

Sobre o ensino de português na escola. In: GERALDI, J.W. (Org.). O texto na sala de aula. $5^{\text {a }}$ ed. São Paulo: Ática, 2011 [1984].

O dado dado e o dado dado. In: PEREIRA DE CASTRO, Maria Fausta. O método e o dado no estudo da linguagem. Campinas: Ed. da Unicamp, 1996. 
RINCÓN, Lenin González. Neocolonialismo pedagógico VS Educación libertadora nuestroamericana. In: Portal Aporrea. Disponível

em: https://www.aporrea.org/educacion/a186225.html

SILVA, Tomaz Tadeu da. Documentos de identidade: uma introdução às teorias do currículo. Belo Horizonte: Autêntica, 2009.

TIKLY, Leon. Globalisation and Education in Postcolonial World: towards a concepyual framework. Comparative Education, Vol 37, No. 2, 2001 pp. 151-171. Disponível em: http://www2.fiu.edu/ ilonl/publications/globalisation\%20and\%20education.pdf

TRAVAGLIA, Luiz Carlos. Gramática e interação: uma proposta para o ensino de gramática no $1^{\circ}$ e $2^{\circ}$ graus. São Paulo: Cortez, 1996.

VASCONCELOS, Maria Lúcia M. C.; BRITO, Helena Pires de. Conceitos de educação em Paulo Freire. 3. ed. Petrópolis/RJ: Vozes; São Paulo: Mack Pesquisa, Fundo Mackenzie de Pesquisa, 2009. 